Jurnal Dinamika Sosial Ekonomi Vol.20 No.2, Desember 2019 : 173-187

ISSN 1411-593X (print)

\title{
STRATEGI PENGEMBANGAN POTENSI DESA WISATA SANGUREJO DI KECAMATAN TURI KABUPATEN SLEMAN
}

\author{
Potential Development Strategy of Sangurejo Tourism Village in Turi District \\ Sleman Regency \\ Nurdin Prasetya*, Budiarto, Teguh Kismantoroadji \\ Program Studi Agribisnis Fakultas Pertanian Universitas Pembangunan Nasional \\ "Veteran" Yogyakarta \\ Jl. SWK 104 Lingkar Utara Condong Catur Yogyakarta Indonesia 55283 \\ email korespondensi: nurdinprasetya24@gmail.com
}

Diterima tanggal : 8 September 2019 ; Disetujui tanggal : 14 November 2019

\begin{abstract}
Sangurejo Tourism Village is a pioneered tourist attraction that requires a development strategy. 1) Analyzing the formulation of the Sangurejo Tourism Village development strategy in Sleman Regency based on IE analysis and SWOT analysis. 2) Determine the right strategic decisions in the development of the Sangurejo Tourism Village in Sleman Regency. This research uses a descriptive method. Data collection techniques in this study through observation, interviews, questionnaires and documentation. The analysis technique used to study the formulation of tourism village development strategies using the SWOT Matrix and IE Matrix. To find out the right strategy for the development of tourist villages using QSPM Matrix analysis. The results of this study indicate that: 1) The formulation of the Sangurejo Tourism Village development strategy by utilizing the strength and development of opportunities is a product development strategy, increasing promotion, and helping with stakeholders. Sangurejo Tourism Village is in a position of growth and development using product development strategies and market penetration. 2) The right strategic decision for developing Sangurejo Tourism Village is market penetration strategy.
\end{abstract}

Keywords: Management Strategy, IE matrix, SWOT matrix, QSPM matrix.

\begin{abstract}
ABSTRAK
Desa Wisata Sangurejo merupakan objek wisata yang baru dirintis yang memerlukan strategi pengembangan. Penelitian ini bertujuan untuk 1) Menganalisis rumusan strategi pengembangan Desa Wisata Sangurejo di Kabupaten Sleman berdasarkan analisis IE dan analisis SWOT. 2) Menentukan keputusan strategi yang tepat dalam pengembangan Desa Wisata Sangurejo di Kabupaten Sleman. Penelitian ini menggunakan metode deskriptif. Teknik pengumpulan data dalam penelitian ini
\end{abstract}


melalui observasi, wawancara, kuisioner dan dokumentasi. Teknik analisis yang digunakan untuk mengetahui rumusan strategi pengembangan desa wisata menggunakan Matriks SWOT dan Matriks IE. Untuk mengetahui strategi yang tepat bagi pengembangan desa wisata menggunakan analisis Matriks QSPM. Hasil penelitian ini menunjukkan bahwa: 1) Rumusan strategi pengembangan Desa Wisata Sangurejo dengan menanfaatkan kekuatan dan berkonsentrasi pada peluang adalah strategi pengembangan produk, meningkatkan promosi, dan bekerjasama dengan stakeholder. Desa Wisata Sangurejo yang berada pada posisi tumbuh dan berkembang menggunakan alternatif strategi pengembangan produk dan penetrasi pasar. 2) Keputusan strategi yang tepat bagi pengembangan Desa Wisata Sangurejo adalah strategi penetrasi pasar.

Kata Kunci: Manajemen strategi, matriks IE, matriks SWOT, matriks QSPM.

\section{PENDAHULUAN}

Pariwisata merupakan berbagai kegiatan yang berhubungan dengan tempat wisata, rekreasi, objek, dan daya tarik wisata serta usaha lainnya yang terkait. Pengembangan pariwisata pada hakikatnya, merupakan upaya dalam mewujudkan pemanfaatan berbagai sumber daya pariwisata dan mengintegrasikan berbagai aspek di luar pariwisata itu sendiri yang berkaitan secara langsung maupun tidak langsung akan keberlangsungan pengembangan objek wisata tersebut.

Desa Wisata Sangurejo merupakan desa wisata yang baru diresmikan tahun 2016. Penentuan strategi pengembangan desa wisata untuk menarik minat wisatawan berkunjung dan agar dapat bersaing dengan desa wisata lain harus benar-benar tepat. Adanya strategi pengembangan Desa Wisata Sangurejo dapat menciptakan keunikan desa wisata dan menjadi karakteristik desa wisata yang akan menjadi daya tarik bagi wisatawan. Pada Tahun 2011 dibangun Embung Kaliaji sebagai irigasi daerah sangurejo dan sekitarnya. Pada Tahun 2014 sampai 2015 dilakukan rehabilitasi Embung Kaliaji. Tahun 2016 dilakukan pengorganisasian oleh pemerintah pariwisata kepada masyarakat Desa Sangurejo sebagai pengurus desa wisata. Tahun 2017, dilakukan pembangunan pendopo, gazebo, menjadikan kebun salak sebagai daya tarik wisata edukasi desa wisata, pembangunan fisik seperti peta wilayah, lampu penerangan jalan, serta memanfaatkan media masa sebagai pemasaran desa wisata. 
Tahun 2018, memanfaatkan budaya jemparingan jawi dan silat sebagai daya tarik Desa Wisata Sangurejo. Adapun visi desa wisata adalah memperkenalkan serta melestarikan adat budaya sebagai peninggalan leluhur dan juga budaya bangsa. Sedangkan misi desa wisata adalah mampu meningkatkan ekonomi masyarakat dan lebih mengenal luaskan Desa Wisata Sangurejo sebagai kampung tujuan wisata berbasis alam dan budaya.

Setelah mengetahui faktor-faktor eksternal dan internal desa wisata berdasarkan peluang, ancaman, kekuatan dan kelemahan yang dihadapi, maka dapat diambil langkah-langkah selanjutnya dalam mengembangkan desa wisata, termasuk memilih strategi yang tepat. Posisi strategis ini dapat diperoleh dari matrikss Internal Eksternal. Untuk memaksimalkan kekuatan dan peluang, serta meminimalkan kelemahan dan ancaman perlu dilakukan analisis IE dan analisis SWOT. Kemudian tahap pengambilan keputusan yang tepat menggunakan matrikss QSPM, karena matrikss QSPM menentukan daya tarik relatif dari berbagai strategi berdasarkan seberapa jauh faktor keberhasilan kunci internal dan eksternal dimanfaatkan atau diperbaiki.

Desa Wisata Sangurejo merupakan desa wisata perintis yang baru dbentuk Tahun 2016, dan daerah wisata memiliki potensi-potensi, sehingga memerlukan strategi yang tepat untuk pengembangan, maka penelitian ini bertujuan untuk menganalisis rumusan strategi pengembangan Desa Wisata Sangurejo di Kecamatan Turi Kabupaten Sleman, serta menentukan strategi yang tepat dalam pengembangan Desa Wisata Sangurejo di Kecamatan Turi Kabupaten Sleman.

\section{METODE PENELITIAN}

Metode dasar penelitian yang digunakan dalam penelitian ini adalah metode deskriptif. Metode desktiptif menurut Nazir (2011) adalah metode dalam meneliti status sekelompok manusia, suatu objek, suatu set lokasi, suatu sistem pemikiran, ataupun suatu kelas peristiwa pada masa sekarang. 
Penelitian ini dilakukan di Desa Wisata Sangurejo Kabupaten Sleman. Pemilihan tempat penelitian dilakukan berdasarkan studi kasus dengan pertimbangan bahwa desa wisata merupakan desa wisata perintis yang baru dibentuk Tahun 2016, dan daerah wisata memiliki potensi-potensi, sehingga memerlukan strategi yang tepat untuk pengembangan Desa Wisata Sangurejo.

Jenis dan sumber data dalam penelitian ini adalah data primer dan data sekunder. Data primer merupakan data yang didapat dari sumber pertama baik dari individu atau perseorangan yaitu hasil dari wawancara atau hasil pengisian kuisioner yang biasa dilakukan oleh peneliti. Data primer diperoleh dari pengurus Desa Wisata Sangurejo. Data sekunder merupakan data pelengkap dari data primer, yaitu data yang diperoleh dari literatur, internet, artikel, jurnal, ilmiah, buku cetak, dan penelitian sebelumnya.

Populasi dalam penelitian ini adalah pengurus Desa Wisata Sangurejo. Penentuan responden menggunakan metode purposive sampling, artinya peneliti hanya melakukan pengambilan data dari responden yang sesuai dengan kriteria dari peneliti. Penelitian ini mengambil data dari responden dengan kriteria khusus yaitu responden yang ahli di bidang yang sesuai dengan kebutuhan penelitian. Responden yang diambil dalam penelitian ini yaitu tujuh (7) orang yang terdiri dari pengurus Desa Wisata Sangurejo. Metode pengumpulan data dilakukan dengan metode observasi, kuisioner, wawancara, dokumentasi.

Teknik analisis data dalam penelitian ini dilakukan dalam tiga tahap, yaitu tahap input, tahap pencocokan, dan tahap keputusan. Pada tahap input, analisis data dimulai dengan mengidentifikasi faktor eksternal dan internal. Faktor eksternal berupa peluang dan ancaman, sedangkan faktor internal berupa kekuatan dan kelemahan. Penerapan strategi pengembangan Desa Wisata Sangurejo didasarkan pada perhitungan matriks evaluasi faktor eksternal (EFE) dan matriks evaluasi faktor internal (EFI), dengan didasari pada kuisioner terbuka, dengan masing-masing faktor 
diberi bobot nilai. Alat yang digunakan dalam tahap pencocokan data adalah matriks analisis IE dan SWOT.

\section{Strategi Pengembangan Desa Wisata Sangurejo Berdasarkan Matriks SWOT \& IE}

Matriks SWOT adalah sebuah alat pencocokan yang penting yang membantu para manager mengembangkan empat jenis strategi. Strategi SO (kekuatan-peluang), memanfaaatkan kekuatan internal untuk menarik keuntungan dari peluang eksternal. Strategi WO (kelemahan peluang) bertujuan untuk memperbaiki kelemahan internal dengan mengambil keuntungan dari peluang eksternal. Strategi ST (kekuatanancaman) menggunakan kekuatan sebuah perusahaan untuk menghindari atau mengurangi dampak ancaman eksternal. Strategi WT (kelemahan-ancaman) merupakan taktik defensif yang diarahkan untuk mengurangi kelemahan internal serta menghindari ancaman eksternal.

Matriks IE memosisikan berbagai divisi suatu organisasi dalam tampilan sembilan sel. Pertama, untuk divisi yang termasuk dalam kuadran I, II, IV berada pada posisi tumbuh dan berkembang. Strategi yang direkomendasikan dalam posisi ini adalah penetrasi pasar, pengembangan pasar, dan pengembangan produk, integrasi ke depan, integrasi ke belakang, dan integrasi horizontal. Kedua, untuk divisi yang termasuk dalam kuadran III, V, VII dapat dikelola dengan bertahan dan memelihara. Strategi yang direkomendasikan yaitu penetrasi pasar, dan pengembangan produk. Ketiga, untuk divisi yang termasuk dalam kuadran VI, VIII, IX strategi yang direkomendasikan dalam posisi ini adalah menghemat atau melakukan divestasi.

Strategi yang Tepat dalam Pengembangan Desa Wisata Sangurejo berdasarkan Matriks QSPM

Menurut David (2009), analisis matriks QSPM dirancang untuk mendapatkan daya tarik relatif dari tindakan alternatif yang layak. Teknik ini secara sasaran menunjukan strategi alternatif mana yang terbaik. Sifat positif yang lain dari QSPM adalah bahwa strategi yang dapat diperiksa secara berurutan atau bersamaan 
Prasetya et.al. / Jurnal Dinamika Sosial Ekonomi Vol.20 No.2, Desember 2019

dan tidak ada batasan untuk jumlah strategi yang dapat dievaluasi atau diperiksa sekaligus. Matriks QSPM menentukan daya tarik dari berbagai strategi yang dibangun berdasarkan faktor-faktor keberhasilan penting internal dan eksternal. Strategi yang dibangun pada Matriks QSPM berasal dari reduksi strategi alternatif pada tahap pencocokan, yaitu Matriks SWOT dan Matriks IE.

\section{HASIL DAN PEMBAHASAN}

Strategi Pengembangan Desa Wisata Sangurejo Berdasarkan Analisis Matriks SWOT dan IE

Strategi pengembangan Desa Wisata Sangurejo pada tahap input, terdiri dari 10 faktor kunci internal yang meliputi 6 faktor kekuatan dan 4 faktor kelemahan. Pada faktor kunci eksternal terdiri dari 10 faktor yang meliputi 6 faktor peluang dan 4 faktor ancaman. Hasil identifikasi faktor internal dan faktor eksternal terdapat pada tabel 1 dan 2.

Tabel 1. Matriks Evaluasi Faktor Internal

\begin{tabular}{|c|c|c|c|}
\hline Faktor-faktor Internal & Bobot & Rating & Skor \\
\hline \multicolumn{4}{|l|}{ Kekuatan: } \\
\hline $\begin{array}{l}\text { Terdapat pendopo, dan embung kaliaji, serta } \\
\text { fasilitas desa wisata }\end{array}$ & 0,11 & 4,00 & 0,440 \\
\hline $\begin{array}{l}\text { Desa yang asri sebagai bumi perkemahan, } \\
\text { outbond, dan wisata alam }\end{array}$ & 0,12 & 4,00 & 0,480 \\
\hline $\begin{array}{l}\text { Kebun salak sebagai edukasi dan pemancingan } \\
\text { embung Kaliaji }\end{array}$ & 0,10 & 3,57 & 0,357 \\
\hline Produksi olahan salak masyarakat & 0,07 & 3,29 & 0,230 \\
\hline Keterampilan masyarakat dalam kebudayaan & 0,11 & 3,86 & 0,386 \\
\hline \multicolumn{4}{|l|}{$\begin{array}{l}\text { Sanggar silat, panahan jemparingan jawi, dan Tari } \\
\text { Badui. }\end{array}$} \\
\hline Pembukuan catatan keuangan & 0,11 & 3,71 & 0,408 \\
\hline Jumlah & 0,61 & 22,43 & 2,301 \\
\hline \multicolumn{4}{|l|}{ Kelemahan: } \\
\hline Pembagian kerja pengurus kurang baik & 0,11 & 1,58 & 0,174 \\
\hline $\begin{array}{l}\text { Kurangnya penggunaan teknologi informasi } \\
\text { sebagai media promosi }\end{array}$ & 0,10 & 2,00 & 0,200 \\
\hline Lokasi kurang strategis & 0,08 & 1,86 & 0,186 \\
\hline
\end{tabular}




\begin{tabular}{lrrr}
\multicolumn{1}{c}{ Kurangnya keterampilan SDM desa wisata } & 0,10 & 1,71 & 0,171 \\
\hline Jumlah & 0,39 & 7,15 & 0,731 \\
\hline Total & 1,00 & 29,58 & 3,032 \\
\hline Sub
\end{tabular}

Sumber : Analisis Data Primer (2019)

Berdasarkan matriks Evaluasi Faktor Internal pada tabel 1, total skor sebesar 3,032, yang berarti lebih besar dari 2,5, hal tersebut menunjukkan bahwa Desa Wisata Sangurejo dalam menghadapi dinamika lingkungan internal posisi perusahaan relatif kuat (David, 2016). Pada variabel kekuatan, skor tertinggi adalah terdapat desa yang asri sebagai bumi perkemahan, outbond, dan wisata alam sebesar 0,480. Desa yang asri sebagai bumi perkemahan, outbond, dan wisata alam akan meningkatkan minat wisatawan yang berkunjung dan menjadi ciri khas dan pembeda dengan desa wisata lainnya.

Pada variabel kelemahan skor tertinggi adalah kurangnya penggunaan teknologi informasi sebagai media promosi sebesar 0,200. Promosi merupakan suatu hal yang sangat penting bagi pengembangan desa wisata. Tanpa adanya promosi akan sangat sulit mendatangkan wisatawan untuk berkunjung.

Tabel 2. Matriks Evaluasi Faktor Eksternal

\begin{tabular}{lrrr}
\hline \multicolumn{1}{c}{ Faktor-faktor Eksternal } & Bobot & Rating & \multicolumn{1}{c}{ Skor } \\
\hline Peluang: & & & \\
$\quad$ Dukungan kebijakan pemerintah daerah & 0,10 & 3,14 & 0,314 \\
Jumlah wisatawan lokal meningkat & 0,11 & 3,00 & 0,330 \\
Jumlah wisatawan asing meningkat & 0,09 & 2,00 & 0,180 \\
Penggunaan teknologi informasi dengan website & 0,12 & 4,00 & 0,480 \\
Tren back to nature yang diminati wisatawan & 0,11 & 3,56 & 0,392 \\
$\quad$ Yogyakarta terkenal sebagai daerah wisata & 0,12 & 3,14 & 0,376 \\
\hline Jumlah & 0,65 & 18,84 & 2,072 \\
\hline Ancaman: & & & \\
$\quad$ Persaingan desa wisata lainnya & 0,10 & 3,23 & 0,323 \\
$\quad$ Letusan gunung merapi & 0,08 & 2,00 & 0,160 \\
$\quad$ Kenakalan Remaja & 0,10 & 2,43 & 0,243 \\
$\quad$ Curah hujan yang tidak menentu & 0,07 & 2,14 & 0,150 \\
\hline Jumlah & 0,35 & 9,80 & 0,876 \\
\hline Total & 1,00 & 28,64 & 2,948 \\
\hline Sur : Annla
\end{tabular}

Sumber : Analisis Data Primer (2019) 
Berdasarkan matriks EFE, total skor sebesar 2,948 yang berarti lebih besar dari 2,5, hal tersebut menunjukkan bahwa Desa Wisata Sangurejo dalam menghadapi dinamika lingkungan eksternal posisi perusahaan relatif kuat (David, 2016). Pada variabel peluang, skor tertinggi adalah penggunanaan teknologi informasi dengan website sebesar 0,480. Pentingnya penggunaan teknologi informasi dengan website dapat memudahkan wisatawan untuk menemukan informasi mengenai Desa Wisata Sangurejo, baik informasi lokasi, paket wisata, maupun kegiatan yang ada di desa wisata. Pada variabel ancaman yaitu persaingan desa wisata lainnya memiliki skor tertinggi sebesar 0,323 .

Strategi pengembangan Desa Wisata Sangurejo pada tahap pencocokan yang menggunakan matriks SWOT didapatkan 3 macam alternatif strategi pada strategi SO dan WO, serta 2 macam alternatif strategi pada strategi ST dan WT. Desa Wisata Sangurejo dianalisis menggunakan matriks IE didapatkan alternatif strategi pengembangan produk dan penetrasi pasar. Hasil identifikasi Matriks SWOT dan Matriks IE pengembangan Desa Wisata Sangurejo dapat dilihat pada tabel 3 dan gambar 1.

Tabel 3. Matriks SWOT Pengembangan Desa Wisata Sangurejo

Strenghts $(\mathrm{S})$

1. Terdapat pendopo, dan embung kaliaji, serta fasilitas desa wisata.

2. Desa yang asri sebagai bumi perkemahan, outbond, dan wisata alam.

3. Kebun salak sebagai edukasi, dan pemancingan embung Kaliaji.

4. Produksi olahan salak masyarakat

5. Sanggar silat, panahan jemparingan jawi, dan Tari Badui.
Weaknesess (W)

1. Pembagian kerja pengurus kurang baik

2. Kurangnya penggunaan teknologi informasi sebagai media promosi

3. Lokasi kurang strategis

4. Kurangnya keterampilan SDM desa wisata

6. Pembukuan keuangan 


\begin{tabular}{|c|c|c|}
\hline Opportunities $(\mathrm{O})$ & Strategi SO & Strategi WO \\
\hline $\begin{array}{l}\text { 1. Dukungan } \\
\text { kebijakan } \\
\text { pemerintah } \\
\text { daerah }\end{array}$ & $\begin{array}{l}\text { 1. Meningkatkan promosi desa } \\
\text { wisata. (S1, S2, S3, S5, O1, } \\
\text { O4) } \\
\text { 2. Mengembangkan produk }\end{array}$ & $\begin{array}{l}\text { 1. Meningkatkan } \\
\text { manajemen } \\
\text { sumberdaya manusia. } \\
(\mathrm{W} 1, \mathrm{~W} 4, \mathrm{O} 1)\end{array}$ \\
\hline $\begin{array}{l}\text { 2. Jumlah } \\
\text { wisatawan lokal } \\
\text { meningkat } \\
\text { 3. Jumlah }\end{array}$ & $\begin{array}{l}\text { wisata yang inovatif dan } \\
\text { unik. (S2, S3, S4, O1, O5) } \\
\text { 3. Meningkatkan kerjasama } \\
\text { antara stakeholder dan }\end{array}$ & $\begin{array}{l}\text { 2. Pembuatan website } \\
\text { sebagai media } \\
\text { pemasaran desa wisata. } \\
(\mathrm{W} 2, \mathrm{O} 1, \mathrm{O} 4)\end{array}$ \\
\hline $\begin{array}{l}\text { wisatawan asing } \\
\text { meningkat } \\
\text { 4. Penggunaan } \\
\text { teknologi } \\
\text { informasi dengan } \\
\text { website }\end{array}$ & $\begin{array}{l}\text { pengurus. (S2, S3, S5, O1, } \\
\mathrm{O} 2, \mathrm{O} 3, \mathrm{O} 6)\end{array}$ & $\begin{array}{l}\text { 3. Memberikan penunjuk } \\
\text { jalan ke lokasi. (W3, } \\
\text { O1) }\end{array}$ \\
\hline $\begin{array}{l}\text { 5. Tren back to } \\
\text { nature yang } \\
\text { diminati } \\
\text { wisatawan }\end{array}$ & & \\
\hline $\begin{array}{l}\text { 6. Yogyakarta } \\
\text { terkenal sebagai } \\
\text { daerah wisata }\end{array}$ & & \\
\hline Threats $(\mathrm{T})$ & Strategi ST & Strategi WT \\
\hline $\begin{array}{l}\text { 1. Persaingan desa } \\
\text { wisata lainnya } \\
\text { 2. Letusan gunung } \\
\text { merapi }\end{array}$ & $\begin{array}{l}\text { 1. Penetapan harga paket } \\
\text { wisata bersaing. (S2, S3, S5, } \\
\text { T1) }\end{array}$ & $\begin{array}{l}\text { 1. Menghindari terjadinya } \\
\text { kenakalan remaja. } \\
(\mathrm{W} 1, \mathrm{~W} 4, \mathrm{~T} 3)\end{array}$ \\
\hline $\begin{array}{l}\text { 3. Kenakalan } \\
\text { Remaja } \\
\text { 4. Curah hujan yang } \\
\text { tidak menentu }\end{array}$ & $\begin{array}{l}\text { 2. Mempertegas peraturan } \\
\text { desa wisata }(\mathrm{S} 1, \mathrm{~S} 2, \mathrm{~T} 3)\end{array}$ & $\begin{array}{l}\text { 2. Meningkatkan fasilitas } \\
\text { desa wisata. (W3, T1, } \\
\text { T4) }\end{array}$ \\
\hline
\end{tabular}

Pada tabel 3 Matriks SWOT pengembangan Desa Wisata Sangurejo terdapat 3 macam strategi SO, yaitu meningkatkan promosi desa wisata, mengembangkan produk wisata, dan meningkatkan kerjasama stakeholder. Pada strategi WO, terdapat strategi meningkatkan manajemen sumberdaya manusia, website sebagai media pemasaran, dan memberikan penunjuk jalan ke lokasi desa wisata. Pada strategi ST, terdapat strategi harga paket yang bersaing, dan mempertegas peraturan desa wisata. 
Prasetya et.al. / Jurnal Dinamika Sosial Ekonomi Vol.20 No.2, Desember 2019

Pada strategi WT terdapat strategi menghindari terjadinya kenakalan remaja, dan meningkatkan fasilitas desa wisata.

Tabel 4. Nilai Skor dan Nilai Skor Rata-rata Faktor Strategi

\begin{tabular}{lrr} 
Faktor Strategis & Total Nilai Tertimbang & Total Nilai Tertimbang Rata-rata \\
\hline Kekuatan & 2,301 & 0,384 \\
Kelemahan & 0,730 & 0,183 \\
Peluang & 2,072 & 0,345 \\
Ancaman & 0,876 & 0,219 \\
\hline
\end{tabular}

Sumber : Analisis Data Primer (2019)

Dari nilai skor rata-rata pada tabel diatas dapat digunakan sebagai dasar perhitungan strategi SO, WO, ST, dan WT. perhitungan strategi SO, WO, ST, dan WT dapat dilihat pada Tabel 5.

Tabel 5. Perhitungan strategi SO, WO, ST, dan WT

\begin{tabular}{ccc}
\hline \multicolumn{1}{c}{ Kekuatan } & \multicolumn{1}{c}{ Kelemahan } \\
\hline Peluang & SO $=($ Skor rata-rata kekuatan + & WO $=($ Skor rata-rata kelemahan + \\
& peluang $): 2$ & peluang $): 2$ \\
& $=(0,384+0,345): 2$ & $=(0,183+0,345): 2$ \\
& $=0,365$ & $=0,264$ \\
Ancaman & ST $=($ Skor rata-rata kekuatan + & WT $=($ Skor rata-rata kelemahan + \\
& ancaman $): 2$ & ancaman $): 2$ \\
& $=(0,384+0,219): 2$ & $=(0,183+0,219): 2$ \\
& $=0,302$ & $=0,201$
\end{tabular}

Sumber : Analisis Data Primer (2019)

Berdasarkan hasil analisis SWOT diketahui rata-rata strategi SO adalah 0,365; Rata-rata strategi WO 0,264; Rata-rata strategi ST 0,302; Rata-rata strategi WT 0,201. Maka, strategi pengembangan Desa Wisata Sangurejo berdasarkan matriks SWOT berada pada strategi SO.

Berdasarkan matriks IE (internal-eksternal) hasil penelitian diketahui bahwa strategi Desa Wisata Sangurejo berada pada sel IV dengan nilai rata-rata berkisar 3,032-2,948. Dengan demikian, posisi strategi Desa Wisata Sangurejo berada pada kategori tumbuh dan berkembang. Adapun strategi yang dapat dikembangkan adalah 
strategi penetrasi pasar, pengembangan pasar, pengembangan produk, integrasi ke depan, integrasi ke beakang, intgrasi horizontal.

Total Rata-rata Tertimbang IFE

$\begin{array}{ccc}\text { Kuat } & \text { Rata-rata } & \text { Lemah } \\ 3,0-4,0 & 2,0-2,99 & 1,0-1,99\end{array}$

\begin{tabular}{lc|c|c|c|}
\cline { 3 - 4 } & \multicolumn{1}{c|}{ Kuat } & & & \\
Total & $3,0-4,0$ & I & II & III \\
Rata-rata & & Rata-rata \\
Tertimbang & $2,0-2,99$ & IV & V & VI \\
\cline { 3 - 5 } EFE & Lemah & VII & VIII & IX \\
\cline { 2 - 4 } & $1,0-1,99$ & & & \\
\cline { 3 - 5 } & & & &
\end{tabular}

Gambar 1. Analisis Matriks IE Pengembangan Desa Wisata Sangurejo

Strategi integrasi ke depan adalah strategi memperoleh kepemilikian atau meningkatkan kontrol atas distributor dan peritel. Strategi integrasi ke belakang adalah strategi mencari kepemilikan atau meningkatkan kontrol atas pemasok perusahaan. Strategi integrasi horizontal adalah mencari kepemilikan atau meningkatkan kontrol atas pesaing. Strategi pengembangan pasar adalah memperkenalkan produk atau jasa baru ke area geografis yang baru. Strategi penetrasi pasar adalah mencari pembagian pasar yang meningkat untuk produk atau jasa saat ini lewat usaha pemasaran yang lebih hebat. Strategi pengembangan produk adalah mencari penjualan yang meningkat untuk meningkatkan produk atau jasa saat ini atau mengembangkan yang baru. Pada strategi integrasi ke depan, integrasi ke belakang, integrasi horizontal, dan pengembangan pasar memerlukan dana yang besar, serta lebih cocok untuk perusahaan berskala besar, maka strategi yang sesuai dengan Desa Wisata Sangurejo adalah strategi pengembangan produk dan penetrasi pasar. 
Prasetya et.al. / Jurnal Dinamika Sosial Ekonomi Vol.20 No.2, Desember 2019

Strategi yang Tepat dalam Pengembangan Desa Wisata Sangurejo berdasarkan

\section{Matriks QSPM}

Untuk mengetahui strategi yang tepat untuk pengembangan Desa Wisata Sangurejo menggunakan matriks QSPM.

Tabel 5. Matriks QSPM Pengembangan Desa Wisata Sangurejo

\begin{tabular}{|c|c|c|c|c|c|}
\hline \multirow{3}{*}{ Faktor Kunci } & \multirow{3}{*}{ Bobot } & \multicolumn{4}{|c|}{ Alternatif Strategi } \\
\hline & & \multicolumn{2}{|c|}{$\begin{array}{c}\text { Strategi } 1 \\
\text { Pengembangan } \\
\text { Produk }\end{array}$} & \multicolumn{2}{|c|}{$\begin{array}{c}\text { Strategi } 2 \\
\text { Penetrasi } \\
\text { Pasar }\end{array}$} \\
\hline & & $\mathrm{AS}$ & TAS & AS & TAS \\
\hline \multicolumn{6}{|l|}{ Kekuatan: } \\
\hline $\begin{array}{l}\text { Terdapat pendopo, dan embung kaliaji, } \\
\text { serta fasilitas desa wisata }\end{array}$ & 0,11 & 3 & 0,33 & 4 & 0,44 \\
\hline $\begin{array}{l}\text { Desa yang asri sebagai bumi } \\
\text { perkemahan, outbond, dan wisata alam }\end{array}$ & 0,12 & 3 & 0,36 & 4 & 0,48 \\
\hline $\begin{array}{l}\text { Kebun salak sebagai edukasi dan } \\
\text { pemancingan embung Kaliaji }\end{array}$ & 0,10 & 3 & 0,30 & 4 & 0,40 \\
\hline Produksi olahan salak masyarakat & 0,07 & 2 & 0,14 & 4 & 0,28 \\
\hline $\begin{array}{l}\text { Sanggar silat, panahan jemparingan } \\
\text { jawi, dan Tari Badui. }\end{array}$ & 0,10 & 3 & 0,30 & 4 & 0,40 \\
\hline Pembukuan catatan keuangan & 0,11 & 2 & 0,22 & 1 & 0,11 \\
\hline \multicolumn{6}{|l|}{ Kelemahan: } \\
\hline Pembagian kerja pengurus kurang baik & 0,11 & 2 & 0,22 & 2 & 0,22 \\
\hline $\begin{array}{l}\text { Kurangnya penggunaan teknologi } \\
\text { informasi sebagai media promosi }\end{array}$ & 0,10 & 3 & 0,30 & 4 & 0,40 \\
\hline Lokasi kurang strategis & 0,08 & 3 & 0,32 & 2 & 0,16 \\
\hline $\begin{array}{l}\text { Kurangnya keterampilan SDM desa } \\
\text { wisata }\end{array}$ & 0,10 & 1 & 0,10 & 2 & 0,20 \\
\hline \multicolumn{6}{|l|}{ Peluang: } \\
\hline Dukungan kebijakan pemerintah daerah & 0,10 & 2 & 0,20 & 3 & 0,30 \\
\hline Jumlah wisatawan lokal meningkat & 0,11 & 3 & 0,33 & 4 & 0,44 \\
\hline Jumlah wisatawan asing meningkat & 0,09 & 3 & 0,27 & 4 & 0,36 \\
\hline $\begin{array}{l}\text { Penggunaan teknologi informasi dengan } \\
\text { website }\end{array}$ & 0,12 & 3 & 0,36 & 4 & 0,48 \\
\hline
\end{tabular}




\begin{tabular}{|c|c|c|c|c|c|}
\hline \multirow{3}{*}{ Faktor Kunci } & \multirow{3}{*}{ Bobot } & \multicolumn{4}{|c|}{ Alternatif Strategi } \\
\hline & & \multicolumn{2}{|c|}{$\begin{array}{c}\text { Strategi 1 } \\
\text { Pengembangan } \\
\text { Produk }\end{array}$} & \multicolumn{2}{|c|}{$\begin{array}{c}\text { Strategi } 2 \\
\text { Penetrasi } \\
\text { Pasar }\end{array}$} \\
\hline & & AS & TAS & AS & TAS \\
\hline $\begin{array}{l}\text { Tren back to nature yang diminati } \\
\text { wisatawan }\end{array}$ & 0,11 & 3 & 0,33 & 4 & 0,44 \\
\hline $\begin{array}{l}\text { Yogyakarta terkenal sebagai daerah } \\
\text { wisatasebagai daerah wisata }\end{array}$ & 0,12 & 4 & 0,48 & 3 & 0,36 \\
\hline \multicolumn{6}{|l|}{ Ancaman: } \\
\hline Persaingan desa wisata lainnya & 0,10 & 4 & 0,40 & 3 & 0,40 \\
\hline Letusan gunung merapi & 0,08 & 2 & 0,16 & 1 & 0,08 \\
\hline Kenakalan Remaja & 0,10 & 2 & 0,20 & 1 & 0,10 \\
\hline Curah hujan yang tidak menentu & 0,07 & 1 & 0,14 & 1 & 0,07 \\
\hline Total & 1,00 & & 5,30 & & 6,12 \\
\hline
\end{tabular}

Sumber : Analisis Data Primer (2019)

Berdasarkan matriks QSPM diperoleh nilai Total Attractiveness Scores (TAS) pada strategi pengembangan produk sebesar 5,30, sedangkan nilai Total Attractiveness Scores (TAS) pada strategi penetrasi pasar sebesar 6,12. Dengan demikian untuk melakukan pengembangan Desa Wisata Sangurejo dapat melakukan strategi penetrasi pasar dalam hal ini sesuai dengan potensi yang dimiliki Desa Wisata Sangurejo.

Pada faktor-faktor kekuatan Desa Wisata Sangurejo terdapat pendopo, Embung Kaliaji, desa yang asri sebagai bumi perkemahan, tempat outbond, tempat wisata alam, juga terdapat kebun salak sebagai wisata edukasi dan juga pemancingan di Embung Kaliaji. Dengan adanya kekuatan-kekuatan yang menjadi produk wisata dan daya tarik desa wisata tersebut dapat dimanfaatkan melalui peluang yang ada, yaitu penggunaan teknologi informasi dengan website. Penggunaan teknologi dengan website dapat memudahkan calon wisatawan untuk mengetahui informasi-informasi yang terdapat di Desa Wisata Sangurejo. Informasi-informasi yang terdapat dalam website berisi profil Desa Wisata Sangurejo, lokasi Desa Wisata Sangurejo, fasilitas- 
fasilitas yang ada di Desa Wisata Sangurejo, serta produk-produk wisata yang ada di Desa Wisata Sangurejo, sehingga calon wisatawan dapat mencari dan melihat apa yang calon wisatawan inginkan, dan yang dapat mereka dapatkan di Desa Wisata Sangurejo.

Pembuatan website yang dilakukan oleh pengurus Desa Wisata Sangurejo dapat dilakukan dengan bekerjasama dengan stakeholder, yaitu Dinas Pariwisata dan Dinas Komunikasi dan Informasi. Kerjasama yang dilakukan berupa pembuatan alamat website, tampilan homepage, tampilan ikon/konten dalam website, yang dilakukan oleh Dinas Pariwisata dan Dinas Komunikasi dan Informasi. Sedangkan pengurus desa wisata sudah mampu untuk mengganti, menghapus, atau menambah konten yang ada dalam website, sehingga informasi yang diberikan kepada calon wisatawan dapat terus diperbarui.

\section{KESIMPULAN DAN SARAN}

\section{Kesimpulan}

Strategi pengembangan Desa Wisata Sangurejo di Kecamatan Turi Kabupaten Sleman yang memanfaatkan kekuatan dan berkonsentrasi terhadap peluang adalah strategi pengembangan produk, meningkatkan promosi, dan bekerjasama dengan stakeholder. Posisi Desa Wisata Sangurejo berada pada posisi tumbuh dan berkembang, dengan alternatif strategi pengembangan produk dan penetrasi pasar. Strategi yang tepat bagi pengembangan Desa Wisata Sangurejo adalah strategi penetrasi pasar.

\section{Saran}

Meningkatkan promosi kesenian jemparingan jawi, silat, dan Tari Badui yang terdapat di desa wisata menggunakan teknologi informasi dengan membuat website. Pembuatan website dapat dilakukan melalui kerjasama dengan stakeholder, yaitu Dinas Pariwisata dan Dinas Komunikasi dan Informasi. Dengan adanya website dapat memberikan informasi kepada calon wisatawan untuk mencari dan melihat apa yang calon wisatawan inginkan. 


\section{DAFTAR PUSTAKA}

Anggraeni, Imas Ayu. (2018). Strategi Pengembangan Agrowisata Gumur (Gunung Sari Makmur) di Desa Gunung Sari, Kecamatan Bumiaji, Batu. Skripsi. Tidak diterbitkan. Fakultas Pertanian. Universitas Brawijaya: Malang.

David, FR. (2009). Managemen Strategic. Konsep edisi 12. Jakarta: Salemba Empat.

Dharmawa I.M.A, Sarjana I.M, dan Yudhari I.D.A.S. (2014). Strategi Pengembangan Desa Wisata di Desa Belimbing Kecamatan Pupuan Kabupaten Tabanan. Jurnal Agribisnis dan Agrowisata, 3(1) :1-11.

Haridayanto, Irwan Soejanto, dan Intan Berlianti. (2018). Analisis Strategi Pembangunan Desa Wisata di Sentra Pengrajin Keris. Jurnal OPSI, 11(1) : 113.

Kholil, A Yusuf dan Ninin Khoirunnisa. 2018. Strategi Pengembangan Desa Wisata Gubuk lakah. Jurnal Ilmiah Agribisnis dan Ekonomi OPTIMA, 2(1) : 27-40.

Nazir, Moh. 2011. Metode Penelitian. Bogor: Ghalia Indonesia.

Nugraha, Dina Novia Priminingtyas. 2016. Strategi Pengembangan Usaha Kecap Cemara Dengan Metode Blue Ocean Strategy dan Balanced Scorecard Pada UKM Cemara Food, Kecamatan Talun, Kabupaten Blitar. Jurnal Habitat, 27(1): $14-24$.

Palit, Ireine Gratia. Celcius Talumingan, dan Grace A.J. Rumagit. 2017. Strategi Pengembangan Kawasan Agrowisata Rurukan. Jurnal Agri-Sosio Ekonomi, 13(2A) : 21-34.

Pambudi, Siwi Harning, Sunarto, dan Prabang Setyono. 2018. Strategi Pengembangan Agrowisata dalam Mendukung Pembangunan Pertanian Studi Kasus di Desa Kaligono (Dewi Kano) Kecamatan Kaligesing Kabupaten Purworejo. Jurnal Analisis Kebijakan Pertanian, 16(2) : 165-184.

Rangkuti, Freddy. 2017. Teknik Membedah Kasus Bisnis Analisis SWOT. Jakarta: PT Gramedia Pustaka Utama.

Sugiyono. 2016. Metode Penelitian Kuantitatif, Kualitatif dan Kombinasi (Mixed Methods). Bandung: Alfabeta

Utomo, Slamet Joko, dan Bondan Satriawan. 2017. Strategi Pengembangan Desa Wisata di Kecamatan Karangploso Kabupaten Malang. Jurnal Neo-Bis. 11(2) : 142-153. 